\title{
Sleep-related hypoventilation and hypercapnia in multiple system atrophy detected by polysomnography with transcutaneous carbon dioxide monitoring
}

\author{
Atsuhiko Sugiyama $^{1}$ (D) - Jiro Terada ${ }^{2} \cdot$ Yu Shionoya $^{3} \cdot$ Shigeki Hirano $^{1} \cdot$ Tatsuya Yamamoto $^{1,4} \cdot$ Yoshitaka Yamanaka $^{1,5}$. \\ Nobuyuki Araki ${ }^{1} \cdot K_{\text {Ken Koshikawa }}{ }^{3}$ Hajime Kasai ${ }^{3} \cdot$ Shinobu Ikeda $^{6}$ - Jiaqi Wang ${ }^{1}$ Kyosuke Koide ${ }^{1}$. Shoichi Ito ${ }^{1,7}$. \\ Satoshi Kuwabara ${ }^{1}$
}

Received: 3 September 2021 / Revised: 4 December 2021 / Accepted: 7 January 2022 / Published online: 13 January 2022

(c) The Author(s), under exclusive licence to Springer Nature Switzerland AG 2022

\begin{abstract}
Purpose We aimed to evaluate sleep-related hypoventilation in multiple system atrophy (MSA) using polysomnography (PSG) with transcutaneous partial pressure of carbon dioxide $\left(\mathrm{PtcCO}_{2}\right)$ monitoring.

Methods This prospective study included 34 patients with MSA. Motor and autonomic function, neuropsychological tests, PSG with $\mathrm{PtcCO}_{2}$ monitoring, and pulmonary function tests were performed. Sleep-related hypoventilation disorder (SRHD) was defined according to the International Classification of Sleep Disorders, third edition.

Results Nine (27\%) of the 34 patients met the diagnostic criteria of SRHD. Twenty-nine (85\%) patients had sleep-related breathing disorders based on an Apnea-Hypopnea Index of $\geq 5 / \mathrm{h}$. The patients with MSA and SRHD had a higher arousal index $(p=0.017)$ and obstructive apnea index $(p=0.041)$ than those without SRHD. There was no difference in the daytime partial pressure of carbon dioxide in arterial blood or respiratory function between MSA patients with and without SRHD. Conclusion Sleep-related hypoventilation may occur in patients with MSA even with a normal daytime partial pressure of carbon dioxide. This can be noninvasively detected by PSG with $\mathrm{PtcCO}_{2}$ monitoring. SRBD and sleep-related hypoventilation are common among patients with MSA, and clinicians should take this into consideration while evaluating and treating this population.
\end{abstract}

Keywords Carbon dioxide $\cdot$ Hypercapnia $\cdot$ Neuropsychological tests $\cdot$ Respirator function tests $\cdot$ Sleep

Atsuhiko Sugiyama

asugiyama@chiba-u.jp

1 Department of Neurology, Graduate School of Medicine, Chiba University, 1-8-1 Inohana, Chuo-ku, Chiba 260-8677, Japan

2 Department of Pulmonary Medicine, School of Medicine, International University of Health and Welfare (IUHW), Chiba, Japan

3 Department of Respirology, Graduate School of Medicine, Chiba University, Chiba, Japan

4 Department of Rehabilitation, Division of Occupational Therapy, Chiba Prefectural University of Health Sciences, Chiba, Japan

5 Division of Rehabilitation, Kimitsu Central Hospital, Kisarazu, Japan

6 Division of Laboratory Medicine, Chiba University Hospital, Chiba, Japan

7 Department of Medical Education, Graduate School of Medicine, Chiba University, Chiba, Japan

\section{Introduction}

Multiple system atrophy (MSA) is a progressive neurodegenerative disorder characterized by a variable combination of autonomic failure, cerebellar ataxia, and parkinsonian features that are typically poorly responsive to levodopa. Respiratory symptoms, including sleep-related breathing disorders (SRBDs), stridor, and involuntary inspiratory sigh, are part of the clinical spectrum of multiple system atrophy [1]. SRBDs manifest as (1) stridor and obstructive sleep apnea mainly due to upper-airway obstruction and as (2) central sleep apnea, abnormal breathing patterns, including Cheyne-Strokes breathing, and irregular breathing caused by impaired autonomic control of respiration [2]. These symptoms due to impaired automatic control of respiration are commonly found in later disease stages of MSA but can be the primary presenting feature of the disease in some cases [2]. Impaired autonomic control of respiration has 
also been suggested as one of the causes of sudden death in MSA [3].

Respiratory chemosensitivity has an important role in autonomic control of respiration, especially during sleep [4]. Impaired ventilatory response to hypoxemia has been reported in patients with MSA [5], whereas the presence of impaired ventilatory response to hypercapnia in patients with MSA is controversial [5, 6]. A study on chemosensitivity to hypoxemia and hypercapnia measured by the standard rebreathing method in 12 patients with MSA demonstrated the presence of impaired chemosensitivity to hypoxemia despite normal chemosensitivity to hypercapnia [5]. However, a patient with reduced ventilatory response to $\mathrm{CO}_{2}$ inhalation was reported in a case series [6]. Daytime hypoventilation and hypercapnia in patients with MSA have been reported in several studies [7-9]. Impairment of autonomic respiratory control is more likely to become apparent during sleep [10]. However, sleep-related hypoventilation in patients with MSA has not been fully investigated.

The American Academy of Sleep Medicine recommends measurement of the partial pressure of carbon dioxide in arterial blood $\left(\mathrm{PaCO}_{2}\right)$ or monitoring of the transcutaneous partial pressure of carbon dioxide $\left(\mathrm{PtcCO}_{2}\right)$ for diagnosis of sleep-related hypoventilation disorder (SRHD) [11]. Therefore, in the present study, we aimed to evaluate SRHD in patients with MSA using polysomnography (PSG) with $\mathrm{PtcCO}_{2}$ monitoring.

\section{Methods}

\section{Subjects}

This prospective study was approved by the Institutional Review Board of the Chiba University Graduate School of
Medicine, and all patients provided written informed consent. Consecutive patients with MSA admitted to Chiba University Hospital between October 2018 and December 2020 were recruited in this study. The inclusion criterion was clinically possible or probable MSA based on the second consensus statement by Gilman and colleagues [12] (Supplementary Table S1). The exclusion criteria were (1) current or previous history of another neuropsychiatric disorder; (2) insufficient data from PSG, neuropsychological tests, and pulmonary function tests; and (3) $\mathrm{PtcCO}_{2}$ monitoring data could not be analyzed due to motion artifacts. Seven patients were excluded because of current or previous history of other neuropsychiatric disease (two with depression, one with putaminal hemorrhage, one with brain infarction, one with schizencephaly, one with polymicrogyria, and one with Takayasu's arthritis). Six patients were excluded because of incomplete measurement of $\mathrm{PtcCO}_{2}$ due to equipment failure. Three patients were excluded because of insufficient data (one with incomplete PSG due to patient's refusal to continue, one with incomplete neuropsychological tests due to blindness, and one with incomplete neuropsychological and pulmonary function tests due to spread of COVID-19). $\mathrm{PtcCO}_{2}$ monitoring data could not be analyzed due to motion artifacts in three patients. On the basis of these criteria, a total of 34 patients with MSA (probable 27, possible 7) were included in the final analysis of this study (Fig. 1).

At the time of diagnosis of MSA, it was classified according to whether the clinical syndrome was dominated by parkinsonism (MSA-P) or cerebellar ataxia (MSA-C). The severity of motor dysfunctions was evaluated by the Unified Multiple System Atrophy Rating Scale (UMSARS) parts 1 and 2 scores, the International Cooperative Ataxia Rating Scale (ICARS) scores, and Movement Disorder Societysponsored Unified Parkinson's Disease Rating Scale (MDSUPDRS) Part III scores. Cognitive functions were evaluated
Fig.1 Study patient flow diagram. MSA, multiple system atrophy; $\mathrm{PtcCO}_{2}$, transcutaneous partial pressure of carbon dioxide; SRHD, sleep-related hypoventilation disorder

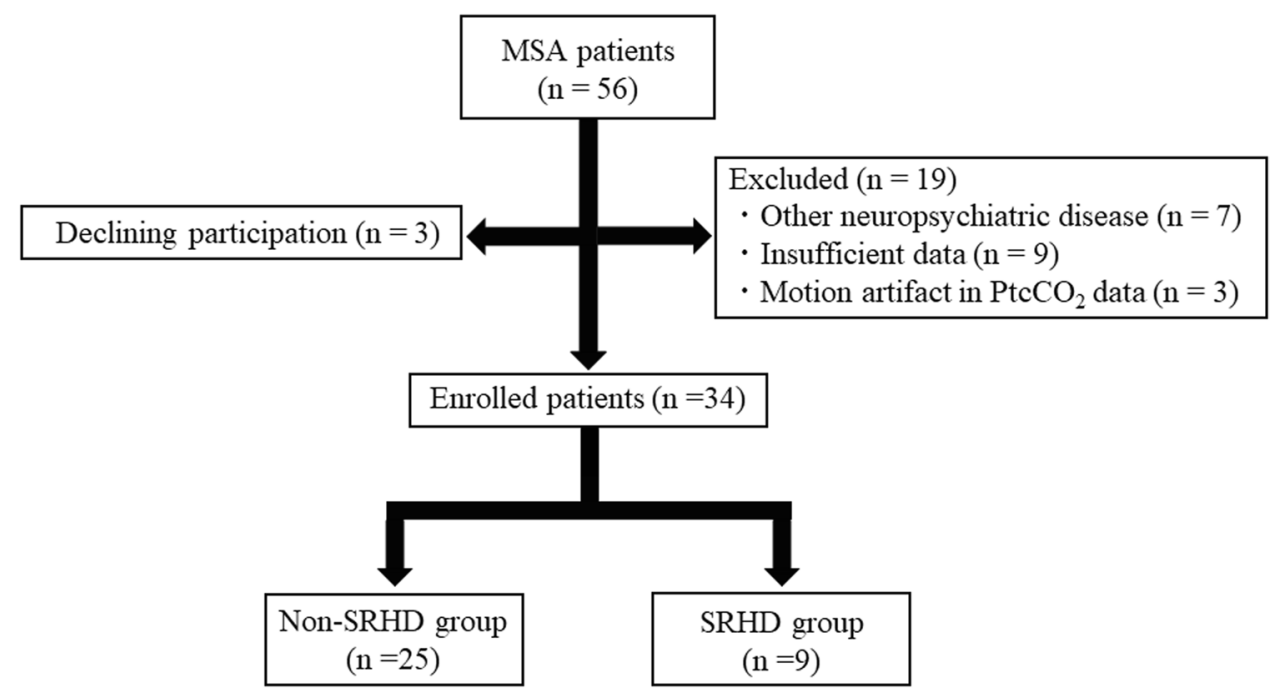


with the Frontal Assessment Battery (FAB), Addenbrooke's Cognitive Examination (ACEIII) [13], and Behavioral Assessment of the Dysexecutive Syndrome (BADS) [14]. The Self-Rating Depression Scale (SDS) and Hamilton Rating Scale for Depression (HAMD-17) [15] were used to evaluate depression. In the autonomic evaluations, urinary symptoms were assessed by using the Overactive Bladder Symptom Score (OABSS) and International Prostate Symptom Score (IPSS). Postvoid residual urine volume was measured three times or more in each subject by ultrasonography, and the mean value was calculated. The head-up tilt test was performed for assessment of orthostatic hypotension as described previously [16].

Olfactory function was assessed by using the Japanese version of the Odor Stick Identification Test (OSIT-J, Daiichi Yakuhin Sangyo Co. Ltd., Japan) [17]. The total number of correct answers to the 12 odors constituted the OSIT-J score. Normal awake $\mathrm{PaCO}_{2}$ was measured by arterial blood gas analysis. History of involuntary inspiratory sigh was assessed by patient interview. Fiberoptic laryngoscopy during wakefulness was performed to assess vocal cord abductor paralysis (VCAP).

The sleep-related symptoms of snoring, headache on waking, sweating, thirst on waking, and apnea were assessed by questionnaire. Daytime sleepiness was assessed by the Epworth Sleepiness Scale score [18]. The REM Sleep Behavior Disorder Screening Questionnaire-Japanese version (RBDSQ-J) was used to assess REM Sleep Behavior Disorder (RBD) [19].

\section{PSG recording and scoring}

All patients underwent standard, full, overnight PSG combined with $\mathrm{PtcCO}_{2}$ monitoring (TCM5 ${ }^{\mathrm{TM}}$, Radiometer, Denmark). Before and after each measurement, the sensor was automatically calibrated in the calibration chamber using a service gas (mixture of $7.5 \% \mathrm{CO}_{2}, 12.0 \% \mathrm{O}_{2}$, and $80.5 \%$ $\mathrm{N}_{2}$ ). The following were recorded: electroencephalography (EEG; C4-M1, O2-M1, C3-M2, 1-M2), electrooculography, anterior tibial electromyography, electrocardiography, respiratory effort by thoracoabdominal piezoelectric belts, nasal airflow by nasal pressure cannula, nasal and oral flow by a thermistor, finger-pulse oximetry, snoring recording by a neck microphone, and assessment of body posture by a thoracic belt sensor. All sleep parameters recorded by PSG were analyzed and scored according to the American Academy of Sleep Medicine Manual for the Scoring of Sleep and Associated Events, version 2.3. Apnea was defined as a reduction in nasal airflow to $<10 \%$ of baseline for $\geq 10 \mathrm{~s}$, whereas hypopnea was defined as a reduction in nasal airflow signal amplitude of $\geq 30 \%$ for $\geq 10 \mathrm{~s}$ in association with either $\mathrm{a} \geq 3 \%$ oxygen desaturation or electroencephalographic arousal. The Apnea-Hypopnea Index (AHI) was counted by the mean number of apneas and hypopneas per hour. SRBD was diagnosed based on an AHI of $\geq 5 / h$. The severity of SRBD was categorized as follows: mild (AHI, 5 to $<15 / \mathrm{h}$ ), moderate (AHI, 15 to $<30 / \mathrm{h}$ ), and severe (AHI, $\geq 30 / \mathrm{h}$ ). Sleep-related hypoventilation disorder (SRHD) was defined as $\mathrm{PtcCO}_{2}>55 \mathrm{mmHg}$ or $>50 \mathrm{mmHg}$ if $\mathrm{PtcCO}_{2}$ increased by $>10 \mathrm{mmHg}$ for $>10 \mathrm{~min}$ of sleep compared with the awake supine value.

\section{Pulmonary function test}

Pulmonary function testing using a CHSTAC-8900 spirometer (Chest MI, Tokyo, Japan) was performed in accordance with the guidelines of the American Thoracic Society and European Respiratory Society [20]. Total lung volume was determined by the helium dilution method, and $\mathrm{DL}_{\mathrm{CO}}$ and alveolar ventilation were determined by the single-breath method. The values for percent predicted forced expiratory volume in $1 \mathrm{~s}\left(\mathrm{FEV}_{1} \%\right)$ were calculated according to the equations of the Japanese Respiratory Society [21].

\section{Nasal airflow analysis in patients with severe SRHD}

Nasal airflow data were analyzed in three patients with severe SRHD who had the longest sleep time with $\mathrm{PtcCO}_{2}>55 \mathrm{mmHg}$. We measured the time at which a decrease in nasal airflow signal amplitude fulfilled the definition of an apnea or hypopnea event during sleep with a $\mathrm{PtcCO}_{2}>50 \mathrm{mmHg}$.

\section{Statistical analysis}

All statistical analyses were performed by using SPSS software, version 25.0 (IBM SPSS Statistics for Windows, IBM Corp.; Armonk, NY). Demographic and clinical, PSG, $\mathrm{PTcCO}_{2}$ monitoring, and pulmonary function test data between the patients with and without SRHD were analyzed by using Student's $t$-test and the Mann-Whitney $U$-test for continuous variables, and Fisher's exact probability test was used for categorical variables. Statistical significance was set at $p<0.05$.

\section{Results}

\section{Overall clinical data and PSG, $\mathrm{PtcCO}_{2}$ monitoring, and pulmonary function tests findings}

The demographic and clinical details of 34 patients with MSA are summarized in Table 1. Among the 34 MSA patients, 20 were MSA-C and 14 were MSA-P. VCAP was 
Table 1 Demographic and clinical data of MSA patients with and without SRHD

\begin{tabular}{|c|c|c|c|c|}
\hline Group & All $(\mathrm{n}=34)$ & Non-SRHD $(n=25)$ & SRHD $(n=9)$ & $p$ value \\
\hline Type of disease (MSA-C/MSA-P) ${ }^{\mathrm{a}}$ & $20 / 14$ & $14 / 11$ & $6 / 3$ & 0.440 \\
\hline Sex $(\text { male/female })^{\mathrm{a}}$ & $20 / 14$ & $12 / 13$ & $8 / 1$ & $\mathbf{0 . 0 3 7}$ \\
\hline Age at PSG, years, mean $\pm \mathrm{SD}^{\mathrm{b}}$ & $65.2 \pm 8.5$ & $65.6 \pm 8.9$ & $64.0 \pm 7.8$ & 0.644 \\
\hline Age at onset, years, mean $\pm \mathrm{SD}^{\mathrm{b}}$ & $62.8 \pm 8.3$ & $63.0 \pm 8.6$ & $62.3 \pm 7.9$ & 0.840 \\
\hline Disease duration, years, median $(\text { range })^{\mathrm{c}}$ & $1.8(0.9-8.6)$ & $1.8(0.9-8.6)$ & $1.7(0.9-2.6)$ & 0.397 \\
\hline BMI, $\mathrm{kg} / \mathrm{m}^{2}$, median (range) ${ }^{\mathrm{c}}$ & $23.1(19.0-29.3)$ & $23.5(20.1-29.3)$ & $22.1(19.0-27.0)$ & 0.788 \\
\hline UMSARS part 1 score, mean \pm SD $^{b}$ & $14.5 \pm 5.5$ & $14.4 \pm 5.9$ & $14.9 \pm 4.7$ & 0.810 \\
\hline UMSARS part 2 score, mean \pm SD $^{b}$ & $14.9 \pm 5.7$ & $15.7 \pm 5.5$ & $12.9 \pm 6.2$ & 0.214 \\
\hline ICARS score, mean $\pm \mathrm{SD}^{\mathrm{b}}$ & $27.3 \pm 12.0$ & $28.0 \pm 11.2$ & $25.3 \pm 14.5$ & 0.576 \\
\hline MDS-UPDRS part 3 score, mean \pm SD $^{b}$ & $27.8 \pm 16.4$ & $31.8 \pm 16.2$ & $16.9 \pm 11.8$ & 0.017 \\
\hline \multicolumn{5}{|l|}{ Cognitive and neuropsychiatric functions } \\
\hline FAB score, mean $\pm \mathrm{SD}^{\mathrm{b}}$ & $13.9 \pm 2.0$ & $14.1 \pm 1.9$ & $13.3 \pm 2.5$ & 0.747 \\
\hline ACE-III score, median (range) ${ }^{c}$ & $90.5(58-97)$ & $92.0(58-97)$ & $90.0(82-93)$ & 0.489 \\
\hline BADS score, mean $\pm \mathrm{SD}^{\mathrm{b}}$ & $90.0 \pm 21.1$ & $89.6 \pm 19.0$ & $91.1 \pm 27.4$ & 0.857 \\
\hline SDS score, mean $\pm \mathrm{SD}^{\mathrm{b}}$ & $44.3 \pm 6.9$ & $43.5 \pm 7.3$ & $46.4 \pm 5.5$ & 0.275 \\
\hline HAM-D17 score, mean $\pm \mathrm{SD}^{\mathrm{b}}$ & $6.2 \pm 3.0$ & $6.2 \pm 2.9$ & $6.0 \pm 3.5$ & 0.840 \\
\hline \multicolumn{5}{|l|}{ Autonomic functions } \\
\hline OABSS, median (range) ${ }^{\mathrm{c}}$ & $4.0(0-11)$ & $4.0(0-11)$ & $5.0(0-10)$ & 0.489 \\
\hline IPSS, median (range) ${ }^{c}$ & $7.0(0-25)$ & $7.0(0-25)$ & $8.0(2-24)$ & 0.280 \\
\hline Postvoid residuals, ml, median $(\text { range })^{\mathrm{c}}$ & $84.5(25.3-401.0)$ & $76.7(25.3-401.0)$ & $142.2(40.6-244.8)$ & 0.140 \\
\hline $\begin{array}{l}\text { Decrease in sBP during head-up tilt test, } \\
\mathrm{mmHg} \text {, mean } \pm \mathrm{SD}^{\mathrm{b}}\end{array}$ & $21.0 \pm 16.2$ & $19.6 \pm 15.5$ & $24.9 \pm 18.5$ & 0.407 \\
\hline $\begin{array}{l}\text { Decrease in dBP during head-up tilt test, } \\
m m H g, \text { median (range) }{ }^{c}\end{array}$ & $6.0(0-46)$ & $6.0(0-39)$ & $10.0(1-46)$ & 0.355 \\
\hline OSIT-J score, median (range) ${ }^{\mathrm{c}}$ & $9.0(2-12)$ & $9.0(4-11)$ & $10.0(2-12)$ & 0.591 \\
\hline VCAP, $n(\%)^{\mathrm{a}}$ & $6(18 \%)$ & $5(21)$ & $1(11)$ & 0.487 \\
\hline Involuntary inspiratory sigh, $n(\%)^{\mathrm{a}}$ & $10(29)$ & $8(32)$ & $2(22)$ & 0.462 \\
\hline
\end{tabular}

$M S A$ multiple system atrophy, $S R H D$ sleep-related hypoventilation disorder, $P S G$ polysomnography, $S D$ standard deviation, $B M I$ body mass index, UMSARS Unified Multiple System Atrophy Rating Scale, ICARS International Cooperative Ataxia Rating Scale, MDS-UPDRS Movement Disorders Society-Unified Parkinson's Disease Rating Scale, FAB frontal assessment battery, ACE-III Addenbrooke's cognitive examination-III, $B A D S$ Behavioural Assessment of the Dysexecutive Syndrome, SDS Zung Self-Rating Depression Scale, HAM-D17 17-item Hamilton Depression Rating Scale, OABSS overactive bladder symptom score, IPSS International Prostate Symptom Score, OSIT-J Japanese version of the odor stick identification test, $V C A P$ vocal cord abductor paralysis

${ }^{a}$ Fisher's exact probability test

${ }^{\mathrm{b}}$ Student's t-test

${ }^{c}$ Mann-Whitney $U$ test

found in six (18\%) patients. Four patients had bilateral partial abduction restriction of the vocal cords, one patient had unilateral partial abduction restriction of the vocal cord, and one patient had unilateral complete abduction restriction of the vocal cord.

Table 2 and Fig. 2 summarize the results of PSG and $\mathrm{PtcCO}_{2}$ monitoring. Twenty-nine $(85 \%)$ patients were diagnosed with SRBD based on an AHI of $\geq 5 / \mathrm{h}$. Eight patients (24\%) had mild SRBD, $12(35 \%)$ were moderate, and $9(27 \%)$ were severe. Nine (27\%) patients met the diagnostic criteria of SRHD. Among them, one did not meet the criterion of SRBD, one was mild, three were moderate, and four were severe. Nasal airflow data during sleep of three patients with severe SRHD (cases 6, 11, and 12 in Fig. 2) and $\mathrm{PtcCO}_{2}>50 \mathrm{mmHg}$ are described in Table 3 and Fig. 3.

The results of the arterial blood gas analysis and pulmonary function tests are presented in Table 3. Two patients did not fulfill the total lung capacity, residual volume, or the diffusion capacity portions of the tests. Daytime hypercapnia (defined as $\mathrm{PaCO}_{2} \geq 45 \mathrm{mmHg}$ ) was observed in five (14.7\%) patients. No MSA patient had severe daytime hypoventilation, defined as $\mathrm{PaCO}_{2}>50 \mathrm{mmHg}$. 
Table 2 Sleep-related symptoms and PSG and $\mathrm{PtcCO}_{2}$ monitoring data

\begin{tabular}{|c|c|c|c|c|}
\hline Group & All $(n=34)$ & Non-SRHD $(n=25)$ & SRHD $(n=9)$ & $p$ value \\
\hline \multicolumn{5}{|l|}{ Sleep-related symptoms } \\
\hline Snoring, $n(\%)^{\mathrm{a}}$ & $24(70.6)$ & $18(72.0)$ & $6(66.7)$ & 0.538 \\
\hline Headache on waking, $n(\%)^{\mathrm{a}}$ & $2(5.9)$ & $0(0)$ & $2(22.2)$ & 0.064 \\
\hline Sweating, $n(\%)^{\mathrm{a}}$ & $9(26.5)$ & $6(24.0)$ & $3(33.3)$ & 0.446 \\
\hline Thirst on waking, $n(\%)^{\mathrm{a}}$ & $15(44.1)$ & $13(52.0)$ & $2(22.2)$ & 0.124 \\
\hline Apnea, $n(\%)^{\mathrm{a}}$ & $12(35.3)$ & $8(32.0)$ & $4(44.4)$ & 0.390 \\
\hline ESS, median (range) ${ }^{\mathrm{b}}$ & $6.0(1-19)$ & $6.0(1-19)$ & $7.0(1-12)$ & 0.280 \\
\hline RBDSQ-J score, median (range) ${ }^{\mathrm{b}}$ & $5.0(1-11)$ & $6.0(2-11)$ & $5.0(1-9)$ & 0.231 \\
\hline \multicolumn{5}{|l|}{ PSG data } \\
\hline Total sleep time, min, mean $\pm \mathrm{SD}^{\mathrm{c}}$ & $523.5 \pm 71.5$ & $510.9 \pm 72.5$ & $558.6 \pm 58.6$ & 0.086 \\
\hline Actual sleep time, min, mean $\pm \mathrm{SD}^{\mathrm{c}}$ & $306.9 \pm 89.2$ & $297.7 \pm 73.3$ & $332.6 \pm 125.1$ & 0.322 \\
\hline Wake time after sleep onset, min, mean $\pm \mathrm{SD}^{\mathrm{c}}$ & $252.0 \pm 83.2$ & $253.8 \pm 65.7$ & $246.9 \pm 124.8$ & 0.835 \\
\hline Arousal index/h, median (range) ${ }^{\mathrm{b}}$ & $34.4(17.1-68.7)$ & $31.2(17.1-68.7)$ & $46.4(28.5-62.6)$ & 0.017 \\
\hline $\mathrm{AHI} / \mathrm{h}$, median $(\text { range })^{\mathrm{b}}$ & $20.0(2.8-86.2)$ & $17.7(2.8-64.1)$ & $25.6(4.5-86.2)$ & 0.072 \\
\hline $\mathrm{AI} / \mathrm{h}$, median (range) ${ }^{\mathrm{b}}$ & $0.7(0-44.8)$ & $0.6(0-44.8)$ & $6.3(0.2-33.1)$ & 0.111 \\
\hline $\mathrm{ObAI} / \mathrm{h}$, median $(\text { range })^{\mathrm{b}}$ & $0.2(0-40.8)$ & $0(0-40.8)$ & $6.3(0-29.9)$ & 0.041 \\
\hline $\mathrm{CnAI} / \mathrm{h}$, median (range) $)^{\mathrm{b}}$ & $0.2(0-2.4)$ & $0.1(0-1.9)$ & $0.2(0-2.4)$ & 0.673 \\
\hline $\mathrm{MxAI} / \mathrm{h}$, median $(\text { range })^{\mathrm{b}}$ & $0(0-7.2)$ & $0(0-7.2)$ & $0(0-2.9)$ & 0.818 \\
\hline $\mathrm{HI} / \mathrm{h}$, median (range) ${ }^{\mathrm{b}}$ & $17.4(2.8-59.0)$ & $15.2(2.8-53.6)$ & $19.3(4.3-59.0)$ & 0.202 \\
\hline SRBD severity ${ }^{\mathrm{a}}$ & & & & 0.533 \\
\hline None, $n(\%)$ & $5(14.7)$ & $4(16.0)$ & $1(11.1)$ & \\
\hline Mild, $n(\%)$ & $8(23.5)$ & $7(28.0)$ & $1(11.1)$ & \\
\hline Moderate, $n(\%)$ & $12(35.3)$ & $9(36.0)$ & $3(33.3)$ & \\
\hline Severe, $n(\%)$ & $9(26.5)$ & $5(20.0)$ & $4(44,4)$ & \\
\hline \multicolumn{5}{|l|}{ Sleep stage } \\
\hline $\mathrm{REM}, \%$, mean $\pm \mathrm{SD}$ & $9.1 \pm 6.2$ & $9.5 \pm 6.6$ & $7.9 \pm 5.3$ & 0.511 \\
\hline $\mathrm{N} 1, \%$, median (range) & $49.3(18.4-90.5)$ & $40.4(18.4-90.5)$ & $51.1(48.0-89.9)$ & 0.120 \\
\hline $\mathrm{N} 2, \%$, mean $\pm \mathrm{SD}$ & $39.6 \pm 17.5$ & $42.4 \pm 18.0$ & $32.0 \pm 14.0$ & 0.129 \\
\hline $\mathrm{N} 3, \%$, median (range) & $0(0-19.5)$ & $0(0-19.5)$ & $0(0-4.1)$ & 0.539 \\
\hline Minimum $\mathrm{SpO}_{2}, \%$, median $\left(\right.$ range) ${ }^{\mathrm{b}}$ & $88.0(75.0-94.0)$ & $88.0(80.0-94.0)$ & $88.0(75.0-94.0)$ & 0.298 \\
\hline Ratio of $\mathrm{SpO}_{2}<90 \%, \%$, median (range) ${ }^{\mathrm{b}}$ & $0.2(0-40.9)$ & $0.2(0-31.6)$ & $0.7(0-40.9)$ & 0.376 \\
\hline REM sleep without atonia, $n(\%)^{\mathrm{a}}$ & $18(52.9)$ & $14(56.0)$ & $4(44.4)$ & 0.417 \\
\hline \multicolumn{5}{|l|}{$\mathrm{PtcCO}_{2}$ monitoring data } \\
\hline Max $\mathrm{PtcCO}_{2}, \mathrm{mmHg}$, mean $\pm \mathrm{SD}^{\mathrm{c}}$ & $48.3 \pm 6.0$ & $45.5 \pm 3.9$ & $56.2 \pm 2.7$ & $<0.001$ \\
\hline Ratio of $\mathrm{PtcCO}_{2}>50 \mathrm{mmHg}, \%$, median (range) ${ }^{\mathrm{b}}$ & $0(0-100.0)$ & $0(0-30.9)$ & $53.5(27.3-100.0)$ & $<0.001$ \\
\hline Ratio of $\mathrm{PtcCO}_{2}>55 \mathrm{mmHg}, \%$, median (range) ${ }^{\mathrm{b}}$ & $0(0-70.4)$ & $0(0-0)$ & $0(0-70.4)$ & 0.050 \\
\hline
\end{tabular}

$P S G$ polysomnography, $\mathrm{PtcCO}_{2}$ transcutaneous partial pressure of carbon dioxide, SRHD sleep-related hypoventilation disorder, ESS Epworth Sleepiness Scale, RBDSQ-J RBD screening questionnaire-Japanese version, $S D$ standard deviation, $A I$ apnea index, $A H I$ apnea hypopnea index, $O b A I$ obstructive apnea index, $C n A I$ central apnea index, $M x A I$ mixed apnea index, $H I$ hypopnea index, $S R B D$ sleep-related breathing disorder, $\mathrm{SpO}_{2}$ arterial oxygen saturation of pulse oximetry, REM rapid eye movement

${ }^{a}$ Fisher's exact probability test

${ }^{\mathrm{b}}$ Mann-Whitney U test

${ }^{\mathrm{c}}$ Student's t-test

\section{Comparison of the clinical data and characteristics of PSG, PtcCO 2 monitoring, and pulmonary function tests between MSA patients with and without SRHD}

A comparison of the clinical data between MSA patients with SRHD (MSA-SRHD) and without SRHD (MSA-nSRHD) is presented in Table 1. The MSA-SRHD group had a higher proportion of males (8/9 in the MSA-SRHD group vs. $12 / 25$ in the MSA-nSRHD group, $p=0.037$ ) and a lower MDS-UPDRS part 3 score $(16.9 \pm 11.8$ in the MSA-SRHD group vs. $31.8 \pm 16.2$ in the MSA-nSRHD group, $p=0.017$ ). There were no significant differences in cognitive, 


\begin{tabular}{|c|c|c|c|c|c|c|c|}
\hline No. & Age & $\begin{array}{c}\text { Type } \\
\text { of MSA }\end{array}$ & $\begin{array}{l}\text { SRBD } \\
\text { severity }\end{array}$ & $\begin{array}{c}\text { AHI } \\
\text { (/hour) }\end{array}$ & Ratio of apnea types and hypopnea & SRHD & $\begin{array}{c}\mathrm{Max} \mathrm{PtcCO}_{2} \\
(\mathrm{mmHg})\end{array}$ \\
\hline 1 & 68 & MSA-C & 3 & 86.2 & & $\mathrm{O}$ & 52.4 \\
\hline 2 & 75 & MSA-C & 3 & 80.0 & & 0 & 55.0 \\
\hline 3 & 62 & MSA-C & 3 & 64.1 & & & 50.2 \\
\hline 4 & 68 & MSA-P & 3 & 54.4 & & & 43.6 \\
\hline 5 & 52 & MSA-P & 3 & 53.1 & & & 41.7 \\
\hline 6 & 61 & MSA-C & 3 & 42.9 & & $\mathrm{O}$ & 59.2 \\
\hline 7 & 63 & MSA-C & 3 & 40.6 & & & 51.5 \\
\hline 8 & 78 & MSA-P & 3 & 32.3 & & & 45.9 \\
\hline 9 & 54 & MSA-C & 3 & 30.9 & & 0 & 54.4 \\
\hline 10 & 70 & MSA-P & 2 & 29.5 & & & 49.3 \\
\hline 11 & 63 & MSA-C & 2 & 25.6 & & 0 & 60.7 \\
\hline 12 & 73 & MSA-P & 2 & 24.8 & & 0 & 56.1 \\
\hline 13 & 71 & MSA-P & 2 & 23.7 & & & 50.6 \\
\hline 14 & 68 & MSA-C & 2 & 22.3 & & & 48.5 \\
\hline 15 & 68 & MSA-P & 2 & 21.9 & & 0 & 54.7 \\
\hline 16 & 66 & MSA-C & 2 & 21.2 & & & 50.4 \\
\hline 17 & 57 & MSA-P & 2 & 20.7 & & & 46.3 \\
\hline 18 & 49 & MSA-C & 2 & 19.3 & & & 49.1 \\
\hline 19 & 64 & MSA-C & 2 & 17.9 & & & 44.0 \\
\hline 20 & 48 & MSA-C & 2 & 17.7 & & & 44.6 \\
\hline 21 & 74 & MSA-P & 2 & 15.0 & & & 43.1 \\
\hline 22 & 69 & MSA-P & 1 & 14.4 & & & 42.4 \\
\hline 23 & 71 & MSA-C & 1 & 12.4 & & & 46.1 \\
\hline 24 & 82 & MSA-P & 1 & 12.3 & & & 46.9 \\
\hline 25 & 52 & MSA-P & 1 & 12.1 & & 0 & 54.7 \\
\hline 26 & 62 & MSA-C & 1 & 9.4 & & & 38.9 \\
\hline 27 & 72 & MSA-P & 1 & 8.1 & & & 39.3 \\
\hline 28 & 66 & MSA-C & 1 & 7.7 & & & 45.7 \\
\hline 29 & 71 & MSA-C & 1 & 7.0 & & & 40.6 \\
\hline 30 & 62 & MSA-C & 0 & 4.5 & & 0 & 58.5 \\
\hline 31 & 69 & MSA-P & 0 & 4.3 & & & 42.1 \\
\hline 32 & 58 & MSA-C & 0 & 3.9 & & & 48.3 \\
\hline 33 & 53 & MSA-C & 0 & 3.5 & & & 48.7 \\
\hline 34 & 76 & MSA-C & 0 & 2.8 & & & 39.1 \\
\hline
\end{tabular}

Obstructive apnea

Fig.2 Results of polysomnography with monitoring of the transcutaneous partial pressure of carbon dioxide $\left(\mathrm{PtCO}_{2}\right)$ in each case. SRBD, sleep-related breathing disorder; AHI, apnea-hypopnea index;
Mixed apnea

Hypopnea
SRHD, sleep-related hypoventilation disorder; MSA-C, cerebellar subtype of multiple system atrophy; MSA-P, parkinsonian subtype of multiple system atrophy 
Table 3 Ratio of each nasal airflow pattern during sleep with $\mathrm{PtcCO} 2>50 \mathrm{mmHg}$

\begin{tabular}{llccl}
\hline & & Apnea (\%) & Hypopnea (\%) & $\begin{array}{l}\text { Unclas- } \\
\text { sifiable } \\
(\%)\end{array}$ \\
\hline Case no & 6 & 22.2 & 15.6 & 62.2 \\
& 11 & 4.3 & 5.1 & 90.6 \\
& 12 & 4.5 & 19.6 & 76.9 \\
\hline
\end{tabular}

Unclassifiable, not meeting definition for either apnea or hypopnea

neuropsychiatric, and autonomic functions between the MSA-SRHD and MSA-nSRHD groups.

Table 2 presents a comparison of the PSG and $\mathrm{PtcCO}_{2}$ monitoring results between the MSA-SRHD and MSAnSRHD groups. In the PSG data, the MSA-SRHD group had a higher arousal index (46.4 [28.5-62.6] in the MSA-SRHD group vs. 31.2 [17.1-68.7] in the MSA-nSRHD group, $p=0.017)$ and obstructive apnea index (6.3 [0.2-33.1] in the MSA-SRHD group vs. 0.6 [0-44.8] in the MSA-nSRHD group, $p=0.041)$. In the $\mathrm{PtcCO}_{2}$ monitoring data, MSASRHD had a higher maximum $\mathrm{PtcCO}_{2}(56.2 \pm 2.7$ in the MSA-SRHD group vs. $45.5 \pm 3.9$ in the MSA-nSRHD group, $p<0.001$ ) and percentage of time with $\mathrm{PtcCO}_{2}>50 \mathrm{mmHg}$ during sleep (53.5 [27.3-100.0] in MSA-SRHD group vs. 0 [0-30.9] in the MSA-nSRHD group, $p<0.001$ ).

A comparison of the arterial blood gas analysis and pulmonary function results between MSA-SRHD and MSAnSRHD is presented in Table 4. There were no differences in the daytime $\mathrm{PaCO}_{2}$ results between the MSA-SRHD and MSA-nSRHD groups $(40.3 \pm 3.5$ vs. $41.7 \pm 3.6 \mathrm{mmHg}$, $p=0.337$ ), indicating that basal ventilation during daytime was not impaired in MSA-SRHD. There was no significant difference in the pulmonary function results between the MSA-SRHD and MSA-nSRHD groups.

\section{Discussion}

Our results show that sleep-related hypoventilation and SRBD were common in patients with MSA, and these should be considered by clinicians during their clinical work-up as non-motor symptoms in patients with MSA.

In our study, SRHD was observed in approximately one-fourth of patients with MSA. The frequency of SRHD and the clinical characteristics of patients with MSA with SRHD have not been adequately studied thus far. There was no difference in daytime $\mathrm{PaCO}_{2}$ or respiratory function between the patients with MSA with SRHD and those without SRHD. Patients with MSA and SRHD had a higher arousal index and obstructive apnea index than those without SRHD. However, some patients with SRHD did not exhibit a high AHI. The analysis of nasal airflow data in patients with
MSA and severe SRHD revealed that the nasal airflow signal did not always meet the definition of an apnea or hypopnea event during sleep with a $\mathrm{PtcCO}_{2}>50 \mathrm{mmHg}$. These findings suggested that SRHD could be overlooked with regular PSG alone and that $\mathrm{PtcCO}_{2}$ monitoring in addition to regular PSG might be important for the evaluation of sleep-related hypoventilation in patients with MSA.

SRBD is frequently observed in patients with MSA. We found that $85 \%$ of patients with MSA had SRBD, defined as an $\mathrm{AHI}$ of $\geq 5 / \mathrm{h}$, which is comparable with previous studies using the same definition of SRBD that reported a prevalence of SRBD ranging from 48.6 to $88.9 \%$ in patients with MSA [22-27]. We also found that $62 \%$ of patients with MSA had moderate to severe SRBD, defined as an AHI of $\geq 15 / \mathrm{h}$, which is consistent with previous studies reporting the prevalence of moderate to severe SRBD, defined as an AHI of $\geq 15 / \mathrm{h}$, ranging from 37.5 to $66.7 \%$ in patients with MSA $[23,26,27]$.

In this study, the pulmonary function test results were not significantly different between patients with MSA with and without SRHD. Our study did not compare the results of pulmonary function in patients with MSA with healthy controls, and there are limited data regarding the pattern of pulmonary function abnormalities in patients with MSA. One study demonstrated an increase in the alveolar-arterial oxygen gradient [9], and another showed a decrease in diffusing capacity in patients with MSA [28]. The mechanism behind these results remains to be elucidated.

Although the underlying pathophysiology of SRHD in patients with MSA remains unclear, SRHD may be caused by the involvement of central chemoreceptive neurons, hypoxia-sensitive carotid chemoreceptors, or autonomic centers controlling vascular tone. First, serotonergic neurons in the medullary raphe nuclei and glutamatergic neurons on the ventral surface of the medulla have been proposed to be responsible for central chemosensitivity to hypercapnia in previous experimental studies [29, 30]. Severe depletion of medullary serotonin neurons has been observed in patients with MSA who succumbed to sudden death [31]. Second, depletion of putative chemosensitive glutamatergic neurons in the arcuate nucleus, located just beneath the ventral medullary surface, has also been reported in MSA [32]. Additionally, depletion of neurokinin-1 receptor-immunoreactive neurons in the rostral ventrolateral medulla of patients with MSA has been reported [33]. Some of these neurons may correspond to the preBötzinger complex neurons implicated in sensitivity to hypoxia. In the present study, the MDSUPDRS Part III score was lower in the MSA-SRHD group than in the MSA-nSRHD group, suggesting that some patients with MSA might have mild degeneration of the nigrostriatal system and severe degeneration of the medullary chemoreceptive neurons or carotid chemoreceptors. Finally, $\mathrm{PtcCO}_{2}$ measures the peripheral partial pressure of 
Fig. 3 Polysomnographic tracing of a patient with severe sleep-related hypoventilation. A Polysomnography shows nasal airflow limitation meeting the definition of obstructive hypopnea during sleep with $\mathrm{PtcCO}_{2}>50 \mathrm{mmHg}$. B Polysomnography shows nasal airflow limitation meeting the definition of hypopnea or apnea is not observed during sleep with $\mathrm{PtcCO}_{2}>50 \mathrm{mmHg}$
(A)

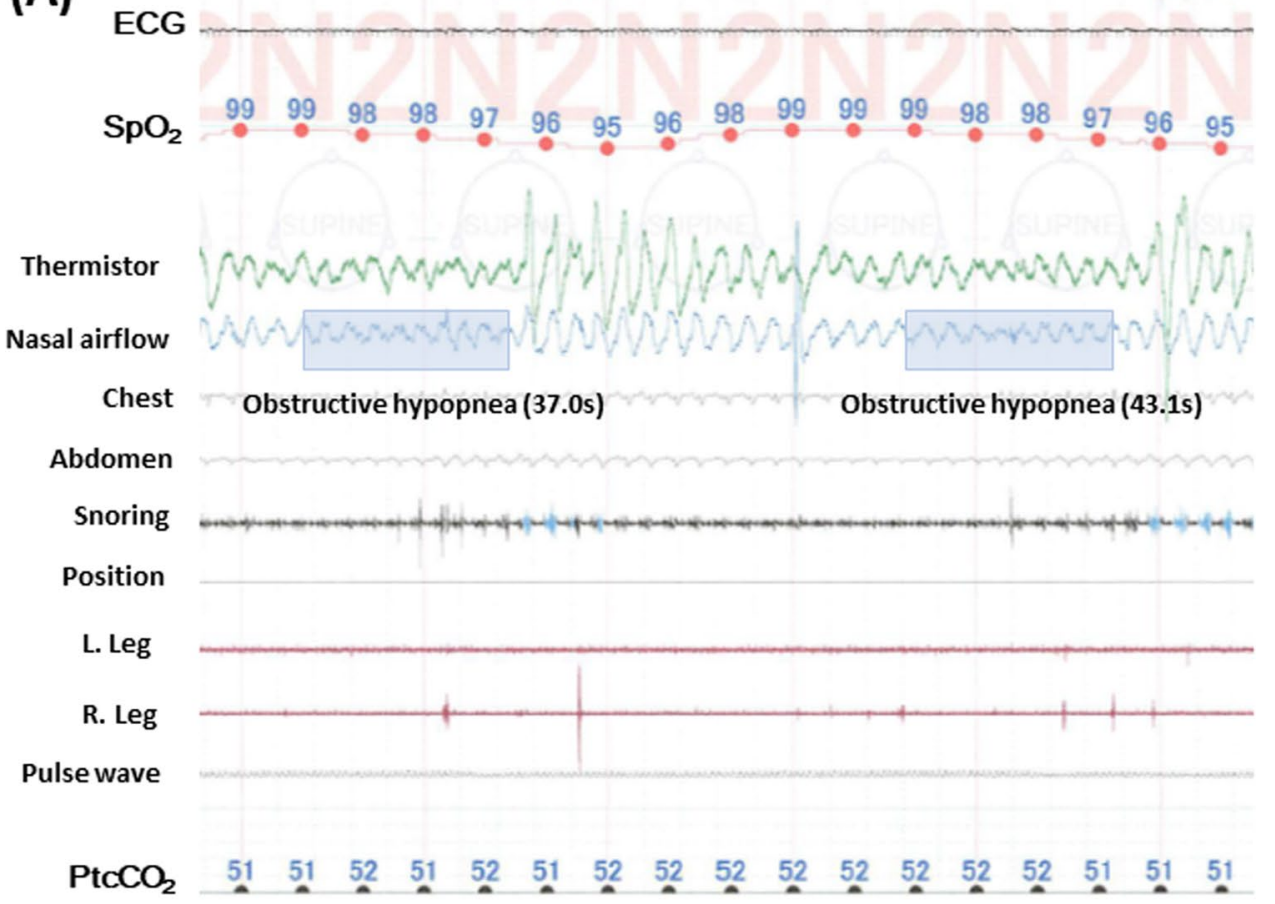

(B)

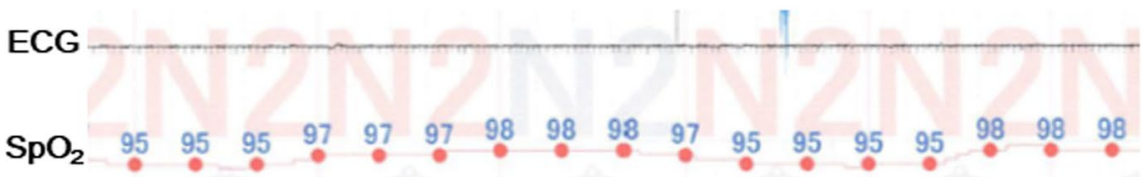

Thermistor

Nasal airflow

Chest

Abdomen

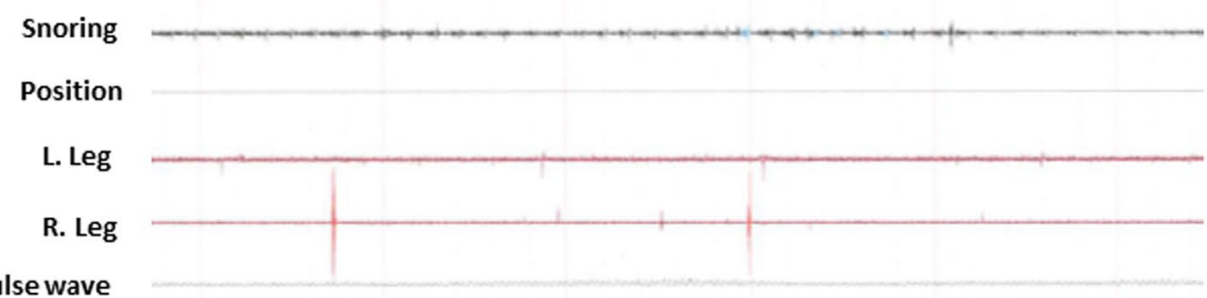

Pulse wave

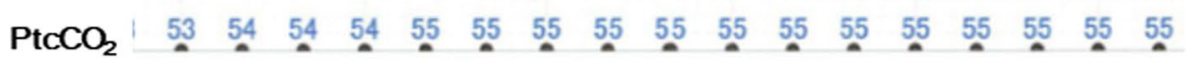

$\mathrm{CO}_{2}$, which increases not only during hypoventilation but also during peripheral hypoperfusion. Therefore, SRHD that manifests only during sleep is also likely to be influenced by sleep-related decreased sympathetic outflow including noradrenergic neurons that control the carotid body [34] or peripheral perfusion $[35,36]$. Therefore, SRHD detected with overnight $\mathrm{PtcCO}_{2}$ monitoring could be a sensitive measure of the degree of the underlying autonomic failure in MSA.

One clinical implication of detecting SRHD using PSG with $\mathrm{PtcCO}_{2}$ monitoring is that noninvasive ventilation (NIV) rather than continuous positive airway pressure (CPAP) may be encouraged to treat SRHD associated with MSA. CPAP is an effective and noninvasive treatment 
Table 4 Arterial blood gas analysis and pulmonary function data

\begin{tabular}{|c|c|c|c|c|}
\hline Group & All & Non-SRHD & SRHD & $p$ value \\
\hline No & 34 & 25 & 9 & \\
\hline Daytime $\mathrm{PaCO}_{2}, \mathrm{mmHg}$, mean $\pm \mathrm{SD}^{\mathrm{a}}$ & $41.3 \pm 3.5$ & $41.7 \pm 3.6$ & $40.3 \pm 3.5$ & 0.337 \\
\hline Daytime hypercapnia, $n(\%)^{\mathrm{b}}$ & $5(14.7)$ & $4(16.0)$ & $1(11.1)$ & 0.600 \\
\hline Daytime $\mathrm{PaO}_{2}, \mathrm{mmHg}$, median (range) ${ }^{\mathrm{c}}$ & $87.0(60-151)$ & $86.0(60-151)$ & $90.0(64-112)$ & 0.908 \\
\hline$\% \mathrm{VC}, \%$, mean $\pm \mathrm{SD}^{\mathrm{a}}$ & $95.1 \pm 13.4$ & $94.6 \pm 12.1$ & $96.8 \pm 17.2$ & 0.677 \\
\hline$\% \mathrm{FVC}, \%$, mean $\pm \mathrm{SD}^{\mathrm{a}}$ & $99.5 \pm 14.2$ & $99.2 \pm 12.9$ & $100.2 \pm 18.1$ & 0.866 \\
\hline$\% \mathrm{FEV} 1, \%$, mean $\pm \mathrm{SD}^{\mathrm{a}}$ & $94.0 \pm 14.6$ & $95.0 \pm 13.4$ & $91.0 \pm 18.2$ & 0.487 \\
\hline $\mathrm{FEV} 1 \%, \%$, mean $\pm \mathrm{SD}^{\mathrm{a}}$ & $94.3 \pm 7.1$ & $95.5 \pm 6.4$ & $91.2 \pm 8.4$ & 0.124 \\
\hline No & 32 & 23 & 9 & \\
\hline$\% \mathrm{RV}, \%$, median (range) ${ }^{\mathrm{c}}$ & $96.2(59.7-178.0)$ & $95.0(59.7-178.0)$ & $104.9(75.1-141.7)$ & 0.301 \\
\hline$\% \mathrm{TLC}, \%$, mean $\pm \mathrm{SD}^{\mathrm{a}}$ & $101.1 \pm 13.0$ & $100.6 \pm 12.2$ & $102.3 \pm 15.5$ & 0.748 \\
\hline$\% \mathrm{DL}_{\mathrm{CO}} / \mathrm{VA}, \%$, mean $\pm \mathrm{SD}^{\mathrm{a}}$ & $100.8 \pm 13.9$ & $101.5 \pm 14.1$ & $99.0 \pm 14.2$ & 0.650 \\
\hline
\end{tabular}

$S R H D$ sleep-related hypopnea disorder, $V C$ vital capacity, $S D$ standard deviation, $F V C$ forced vital capacity, $F E V 1$ forced expiratory volume 1.0 , $R V$ residual volume, $T L C$ total lung capacity, $D L_{C O}$ diffusing capacity for carbon monoxide, $V A$ minute alveolar ventilation

${ }^{\text {a }}$ Student's t-test

${ }^{\mathrm{b}}$ Fisher's exact probability test

${ }^{\mathrm{c}}$ Mann-Whitney U test

option for SRBDs in patients with MSA and has been recommended as standard treatment $[37,38]$. NIV therapy is utilized as an alternative for overcoming ventilatory insufficiency in hypoventilation conditions. NIV has been considered an alternative to CPAP therapy for the treatment of severe obstructive sleep apnea with hypercapnia, certain forms of restrictive lung disease, and hypoventilation syndrome associated with daytime hypercapnia [39, 40]. Based on an algorithm for the treatment of chronic hypercapnic respiratory insufficiency in patients with neuromuscular disease in the German National Guidelines, two of the eight MSA -SRHD patients in this study with morning headache met the indication for NIV [41]. Although the effect of sleeprelated hypoventilation and associated hypercapnia on MSA progression and prognosis has not yet been investigated, hypercapnia has been proposed as one of the factors affecting cognitive function in patients with chronic obstructive pulmonary disease [42]. Additional longitudinal studies are warranted to clarify the effects of sleep-related hypoventilation and associated hypercapnia on disease progression and cognitive impairment in patients with MSA.

Limitations of our study include the following. First, this study lacked a healthy control group. Second, the MSA patients were clinically diagnosed without postmortem confirmation, so it is possible that some of these patients were misdiagnosed. Third, the $\mathrm{PaCO}_{2}$ was measured by the transcutaneous route alone, and arterial blood gas analysis during sleep was not performed. Although direct $\mathrm{PaCO}_{2}$ measurement remains the gold standard, $\mathrm{PtcCO}_{2}$ monitoring has been shown to be a minimally invasive method that provides a reliable estimation of the $\mathrm{PaCO}_{2}[43,44]$. Fourth, in the present study, 22 of the 56 consecutive patients were excluded for various reasons; therefore, unexpected selection bias might have affected the study results. Fifth, the number of patients included in the final analysis was not sufficient to perform reliable multivariable analyses to identify independent factors associated with SRHD.

\section{Conclusions}

In conclusion, $\mathrm{PtcCO}_{2}$ monitoring during PSG may reveal sleep-related hypoventilation in patients with MSA who have normal daytime $\mathrm{PaCO}_{2}$. SRBD and sleep-related hypoventilation are common in patients with MSA, and clinicians should take this into consideration as non-motor symptoms in patients with MSA.

Supplementary Information The online version contains supplementary material available at https://doi.org/10.1007/s11325-022-02568-4.

Acknowledgements The authors sincerely thank Asami Uchida, Eriko Abe, Ami Niwano, Miku Nagasawa, Yuri Imaizumi, and Kazuki Yoshida (Division of Laboratory Medicine, Chiba University Hospital) for their technical support in this research.

Author contribution Conceptualization: Atsuhiko Sugiyama and Jiro Terada. Formal analysis and investigation: Ken Koshikawa, Shinobu Ikeda, Jiaqi Wang, and Kyosuke Koide. Writing—original draft preparation: Atsuhiko Sugiyama, Yu Shionoya, and Hajime Kasai. Writing —revise and editing: Shigeki Hirano, Tatsuya Yamamoto, Yoshitaka Yamanaka, Nobuyuki Araki, Shoichi Ito, and Satoshi Kuwabara. Funding acquisition: Atsuhiko Sugiyama. Supervision: Satoshi Kuwabara. 
Funding This work was supported by the JPPS KAKENHI (Grant Number 18K15438).

Data Availability All data generated or analyzed during this study are included in this article. Further enquiries can be directed to the corresponding author.

Code availability Not applicable.

\section{Declarations}

Ethics approval This prospective study was approved by the Institutional Review Board of the Chiba University Graduate School of Medicine (approval reference number: 3122). This study was performed in line with the principles of the Declaration of Helsinki.

Consent to participate Written informed consent was obtained from all individual participants included in the study.

Consent to publish Not applicable.

Conflict of interest The authors declare no competing interests.

\section{References}

1. Jecmenica-Lukic M, Poewe W, Tolosa E, Wenning GK (2012) Premotor signs and symptoms of multiple system atrophy. Lancet Neurol 11(4):361-368

2. Iranzo A (2007) Sleep and breathing in multiple system atrophy. Curr Treat Options 9(5):347-353

3. Shimohata T, Aizawa N, Nakayama H, Taniguchi H, Ohshima Y, Okumura $\mathrm{H}$ et al (2016) Mechanism and prevention of sudden death in multiple system atrophy. Parkinsonism Relat Disord $30: 1-6$

4. Benarroch EE (2019) Control of the cardiovascular and respiratory systems during sleep. Auton Neurosci 218:54-63

5. Tsuda T, Onodera H, Okabe S, Kikuchi Y, Itoyama Y (2002) Impaired chemosensitivity to hypoxia is a marker of multiple system atrophy. Ann Neurol 52(3):367-371

6. Chokroverty S, Sharp JT, Barron KD (1978) Periodic respiration in erect posture in Shy-Drager syndrome. J Neurol Neurosurg Psychiatry 41(11):980-986

7. Glass GA, Josephs KA, Ahlskog JE (2006) Respiratory insufficiency as the primary presenting symptom of multiple-system atrophy. Arch Neurol 63(7):978-981

8. Shimohata T, Nakayama $\mathrm{H}$, Shinoda $\mathrm{H}$, Tsukada $\mathrm{H}$, Takahashi $\mathrm{S}$, Gejo F et al (2006) Multiple system atrophy with progressive nocturnal hypoxemia: case report with polysomnography and continuous positive airway pressure treatment. Eur Neurol 56(4):258-260

9. Shimohata T, Shinoda H, Nakayama H, Ozawa T, Terajima K, Yoshizawa $\mathrm{H}$ et al (2007) Daytime hypoxemia, sleep-disordered breathing, and laryngopharyngeal findings in multiple system atrophy. Arch Neurol 64(6):856-861

10. McNicholas WT, Rutherford R, Grossman R, Moldofsky H, Zamel N, Phillipson EA (1983) Abnormal respiration pattern generation during sleep in patients with autonomic dysfunction. Am Rev Respir Dis 128(3):429-433

11. American Academy of Sleep Medicine, (2014) The international classification of sleep disorders. $3^{\text {rd }}$ Edition (ICSD-3).

12. Gilman S, Wenning GK, Low PA, Brooks DJ, Mathias CJ, Trojanowski JQ et al (2008) Second consensus statement on the diagnosis of multiple system atrophy. Neurology 71(9):670-676
13. Takenoshita S, Terada S, Yoshida H, Yamaguchi M, Yabe M, Imai $\mathrm{N}$ et al (2019) Validation of Addenbrooke's cognitive examination III for detecting mild cognitive impairment and dementia in Japan. BMC Geriatr 19(1):123

14. Wilson BA, Alderman N, Burgess PW, Emslie H, Evans JJ (1996) Behavioural assessment of the Dysexecutive Syndrome, Thames Valley Test Company, Bury St. Edmunds, UK.

15. Hamilton M (1960) A rating scale for depression. J Neurol Neurosurg Psychiatry 23(1):56-62

16. Sugiyama A, Yokota H, Yamanaka Y, Mukai H, Yamamoto T, Hirano S et al (2020) Vertical pons hyperintensity and hot cross bun sign in cerebellar-type multiple system atrophy and spinocerebellar ataxia type 3. BMC Neurol 20(1):157

17. Iijima M, Osawa M, Momose M, Kobayakawa T, Saito S, Iwata M, Uchiyama S (2010) Cardiac sympathetic degeneration correlates with olfactory function in Parkinson's disease. Mov Disord 25(9):1143-1149

18. Johns MW (1994) Sleepiness in different situations measured by the Epworth Sleepiness Scale. Sleep 17(8):703-710

19. Miyamoto T, Miyamoto M, Iwanami M, Kobayashi M, Nakamura M, Inoue Y et al (2009) The REM sleep behavior disorder screening questionnaire: validation study of a Japanese version. Sleep Med 10(10):1151-1154

20. Celli BR, MacNee W, ATS, ERS Task Force, (2004) Standards for the diagnosis and treatment of patients with COPD: a summary of the ATS/ERS position paper. Eur Respir J 23(6):932-946

21. Guideline of respiratory function tests - spirometry, flow-volume curve, diffusion capacity of the lung (2004) Nihon Kokyuki Gakkai Zasshi J Jpn Respir Soc Suppl:1-56.

22. Jin K, Okabe S, Chida K, Abe N, Kimpara T, Ohnuma A et al (2007) Tracheostomy can fatally exacerbate sleep-disordered breathing in multiple system atrophy. Neurology 68(19):1618-1621

23. Deguchi K, Ikeda K, Goto R, Tsukaguchi M, Urai Y, Kurokohchi $\mathrm{K}$ et al (2010) The close relationship between life-threatening breathing disorders and urine storage dysfunction in multiple system atrophy. J Neurol 257(8):1287-1292

24. Muntean ML, Sixel-Döring F, Trenkwalder C (2013) No difference in sleep and RBD between different types of patients with multiple system atrophy: a pilot video-polysomnographical study. Sleep Disord 2013:258390.

25. Guo XY, Cao B, Lei F, Huang L, Chen K, Song W et al (2013) Clinical and polysomnographic features of patients with multiple system atrophy in Southwest China. Sleep Breath 17(4):1301-1307

26. Cao B, Wei QQ, Ou R, Zhao B, Hu T, Chen Y et al (2018) Impact of sleep-related breathing disorder on motor and non-motor symptoms in multiple system atrophy. Sleep Breath 22(4):981-987

27. Parreira S, Antunes F, Coelho M, Bentes C, Peralta R (2021) Sighs during sleep in multiple system atrophy. Sleep Med 78:75-80

28. Wang Y, Shao WB, Gao L, Lu J, Gu H, Sun LH, et al (2014) Abnormal pulmonary function and respiratory muscle strength findings in Chinese patients with Parkinson's disease and multiple system atrophy-comparison with normal elderly. PLoS ONE 9(12):e116123.

29. Richerson GB (2004) Serotonergic neurons as carbon dioxide sensors that maintain $\mathrm{pH}$ homeostasis. Nat Rev Neurosci 5(6):449-461

30. Benarroch EEE (2007) Brainstem respiratory control: substrates of respiratory failure of multiple system atrophy. Mov Disord 22(2):155-161

31. Tada M, Kakita A, Toyoshima Y, Onodera O, Ozawa T, Morita $\mathrm{T}$ et al (2009) Depletion of medullary serotonergic neurons in patients with multiple system atrophy who succumbed to sudden death. Brain 132(Pt 7):1810-1819 
32. Benarroch EE, Schmeichel AM, Low PA, Parisi JE (2007) Depletion of putative chemosensitivity respiratory neurons in the ventral medullary surface in multiple system atrophy. Brain $130(\mathrm{Pt}$ 2):469-475

33. Benarroch EE, Schmeichel AM, Low PA, Parisi JE (2003) Depletion of ventromedullary NK-1 receptor-immunoreactive neurons in multiple system atrophy. Brain 126(Pt 10):2183-2190

34. Virkki A, Polo O, Gyllenberg M, Aittokallio T (2007) Can Carotid body perfusion act as a respiratory controller? J Theor Biol 249(4):737-748

35. Healey CJ, Fedullo AJ, Swinburne AJ, Wahl GW (1987) Comparisons of noninvasive measurements of carbon dioxide tension during withdrawal from mechanical ventilation. Crit Care Med 15(8):764-768

36. Clark JS, Votteri B, Ariagno RL, Cheung P, Eichhorn JH, Fallat RJ et al (1992) Noninvasive assessment of blood gases. Am Rev Respir Dis 145(1):220-232

37. Iranzo A, Santamaria J, Tolosa E (2000) Continuous positive air pressure eliminates nocturnal stridor in multiple system atrophy. Lancet 356(9238):1329-1330

38. Ghorayeb I, Yekhlef F, Bioulac B, Tison F (2005) Continuous positive airway pressure for sleep-related breathing disorders in multiple system atrophy: long-term acceptance. Sleep Med 6(4):359-362
39. Piper AJ, Sullivan CE (1994) Effects of short-term NIPPV in the treatment of patients with severe obstructive sleep apnea and hypercapnia. Chest 105(2):434-440

40. Kushida CA, Littner MR, Hirshkowitz M, Morgenthaler TI, Alessi CA, Bailey D et al (2006) Practice parameters for the use of continuous and bilevel positive airway pressure devices to treat adult patients with sleep-related breathing disorders. Sleep 29(3):375-380

41. Windisch W, Geiseler J, Simon K, Walterspacher S, Dreher M; on behalf of the Guideline Commission (2018) German National Guideline for treating chronic respiratory failure with invasive and non-invasive ventilation - revised edition 2017: part 2. Respiration 96(1): 171-203.

42. Dodd JW, Getov SV, Jones PW (2010) Cognitive function in COPD. Eur Respir J 35(4):913-922

43. Eberhard P, Gisiger PA, Gardaz JP, Spahn DR (2002) Combining transcutaneous blood gas measurement and pulse oximetry. Anesthe Analg 94(1 Suppl):S76-80

44. Tobias JD (2009) Transcutaneous carbon dioxide monitoring in infants and children. Pediatr Anesth 19(5):434-444

Publisher's note Springer Nature remains neutral with regard to jurisdictional claims in published maps and institutional affiliations. 